\title{
Respiratory System Findings Reference Identifier
}

National Cancer Institute

\section{Source}

National Cancer Institute. Respiratory System Findings Reference Identifier. NCI

Thesaurus. Code C162208.

A character or string that represents a respiratory system findings procedure event reference. 